\title{
De impact van werken met zedenplegers op de professional
}

\section{Resumé van een symposium*}

Julia Wilpert, Marije Keulen-de Vos, Minne De Boeck \& Kasia Uzieblo

\section{Introductie}

Om de druk van de prestatiemaatschappij tegenwicht te bieden is er steeds meer aandacht gekomen voor onze levenskwaliteit. Werk speelt een belangrijke rol bij hoe wij ons fysieke, psychische en sociale functioneren ervaren. Het werk kan echter zowel een bron van tevredenheid als van stress zijn. ${ }^{1}$ Werkstress kan leiden tot klachten als vermoeidheid, spanning, prikkelbaarheid, labiliteit, concentratieverlies, slapeloosheid en uiteindelijk burn-out, een ernstige en langdurende vorm van overspannenheid. ${ }^{2}$ In Nederland had in 2018 gemiddeld één op de vijf werknemers last van burn-outklachten; in 2015 was dit nog één op de zeven. ${ }^{3}$ Afgezien van een verminderde levenskwaliteit voor de betroffene gaan er ook aanzienlijke kosten mee gepaard vanwege onder andere ziekteverzuim. Het is dus ook van maatschappelijk belang om goed zorg te dragen voor het welzijn van werknemers.

Verschillende beroepsgroepen brengen verschillende stressoren met zich; fysieke en emotionele belasting kunnen bijvoorbeeld nogal uiteenlopen naargelang de beroepssetting. Het Centraal Bureau voor de Statistiek (CBS) heeft sinds 2014 jaarlijks een overzicht gepubliceerd van de psychosociale arbeidsbelasting (PSA: factoren in de arbeidssituatie die direct of indirect stress teweegbrengen,

* Julia Wilpert MSc. is onderzoeker bij het centrum voor ambulante forensische ggz de Waag (onderdeel van De Forensische Zorgspecialisten) in Utrecht. Marije Keulen-de Vos PhD is senior onderzoeker bij FPC de Rooyse Wissel in Venray. Minne De Boeck is criminologe aan het Universitair Forensisch Centrum (UFC) in Antwerpen en mede verbonden aan het Collaborative Antwerp Psychiatric Research Institute (CAPRI) van de Universiteit van Antwerpen. Prof. dr. Kasia Uzieblo is als senior onderzoeker verbonden aan De Forensische Zorgspecialisten in Utrecht. Ook is zij als gastprofessor werkzaam bij de Universiteit Gent en de Vrije Universiteit Brussel. Met bijzondere dank aan Linde van Mechelen (Universiteit Gent) en Jeffrey Lauer (Vrije Universiteit Amsterdam) voor hun waardevolle input voor dit symposiumverslag.

1 B. Erdogan e.a., 'Whistle While You Work: A Review of the Life Satisfaction Literature', Journal of Management 2012, 4, p. 1038-1083; R.M. van Rijn e.a., 'Work as Treatment? The Effectiveness of Re-employment Programmes for Unemployed Persons with Severe Mental Health Problems on Health and Quality of Life: A Systematic Review and Meta-analysis', Occupational and Environmental Medicine 2016, 73, p. 275-279.

2 H. van der Molen e.a., Beroepsziekten in cijfers, Amsterdam: Nederlands Centrum voor Beroepsziekten 2018.

3 Centraal Bureau voor de Statistiek 2019, StatLine - Psychosociale arbeidsbelasting (PSA) werknemers, via https://statline.cbs.nl/Statweb/publication/?DM=SLNL\&PA=83157ned\&D1=20\&D2=0 $-1,4-5,19,21-22,25-28,32-33,35,39,42-44,48-51 \& D 3=a \& H D R=G 2, T \& S T B=G 1 \& V W=T$. 
waaronder seksuele intimidatie, agressie en geweld, pesten en werkdruk) per bedrijfstak. Voor de gezondheids- en welzijnszorg en het openbaar bestuur en overheidsdiensten was de PSA in 2018 respectievelijk 17,8\% en 16,2\%; een stijging ten opzichte van 2014 , waarin dit $14,5 \%$ en $15,6 \%$ was. Ter vergelijking: de PSA voor werknemers in de landbouw, bosbouw en visserij was in hetzelfde jaar met $11,2 \%$ het laagst, en in het onderwijs met $23 \%$ het hoogst. 3 De forensische sector wordt beschouwd als een stressvolle, gevaarlijke en emotioneel veeleisende omgeving. Professionals in deze sector lijken meer risico te lopen op werkgerelateerde stress vanwege hun constante blootstelling aan verontrustende maatschappelijke problemen en aan cliënten met extreem uitdagend gedrag. ${ }^{4}$ Een specifieke groep in deze sector vormen de mensen die met zedenplegers werken. Vanwege veelvuldige confrontatie met expliciete informatie over seksueel geweld kunnen zij te maken krijgen met hyperalertheid op hun eigen en andermans gedrag, met name ten opzichte van kinderen, en kunnen zij geconfronteerd worden met opdringerige beelden en gedachten over casusmateriaal. ${ }^{5}$ Dit kan onder meer uitmonden in secundaire traumatisering, ook wel plaatsvervangend trauma genoemd: het getraumatiseerd raken door verhalen van cliënten/patiënten. Ook een dergelijke indirecte manier van getraumatiseerd raken kan leiden tot veranderingen in iemands zelfgevoel, affect, interpersoonlijke relaties en gedrag, en zodoende vergelijkbare klachten opleveren als die van een posttraumatische stressstoornis. ${ }^{6}$ Internationale studies naar ggz-personeel suggereren dat tussen $46 \%$ en $80 \%$ van de mensen die met zedendelinquenten werken, symptomen van secundair trauma in een of andere vorm ervaart. ${ }^{7}$

Hoewel het werken met zedenplegers aanzienlijke consequenties met zich kan brengen, is er nog relatief weinig onderzoek naar dit onderwerp gedaan. Ruime tijd geleden werden in een Amerikaanse studie al aanwijzingen gevonden voor meer emotionele uitputting en depersonalisatie bij behandelaars van zedenplegers. ${ }^{8}$ Tegelijkertijd ondervonden de 86 onderzochte behandelaars een hogere mate van persoonlijke voldoening, indicerend dat het werken met zedenplegers ook een gevoel van effectiviteit kan opleveren, ondanks dat de cliënten moeilijker kunnen zijn. In hetzelfde onderzoek werd ook gekeken naar de setting van de behandelaars. Hieruit bleek dat residentiële behandelaars van zedenplegers een hogere mate van burn-out leken te ervaren dan poliklinische aanbieders. Sekse en aantal jaren werkervaring hadden hier geen significante invloed op. In een kwali-

4 K.A. Elliott \& D. Daley, 'Stress, Coping, and Psychological Well-being Among Forensic Health Care Professionals', Legal and Criminological Psychology 2013, 18, p. 187-204.

5 H.M. Moulden \& P. Firestone, 'Therapist Awareness and Responsibility in Working With Sexual Offenders', Sexual Abuse: A Journal of Research and Treatment 2010, 4, p. 374-386; C. Slater \& I. Lambie, 'The Highs and Lows of Working with Sexual Offenders: A New Zealand Perspective', Journal of Sexual Aggression 2011, 3, p. 320-334.

6 S.R. Jenkins \& S. Baird, 'Secondary Traumatic Stress and Vicarious Trauma: A Validation Study', Journal of Traumatic Stress 2002, 5, p. 423-432.

7 M. Severson \& C. Pettus-Davis, 'Parole Officers' Experiences of the Symptoms of Secondary Trauma in the Supervision of Sex Offenders', International Journal of Offender Therapy and Comparative Criminology 2013, 1, p. 5-24.

8 R.A. Shelby, R.M. Stoddart \& K.L. Taylor, 'Factors Contributing to Levels of Burnout among Sex Offender Treatment Providers', Journal of Interpersonal Violence 2001, 16, p. 1205-1217. 
tatief Amerikaans onderzoek werden 49 reclasseringswerkers van zedendelinquenten gevraagd naar hun ervaringen met symptomen van secundair trauma. De deelnemers rapporteerden een verscheidenheid aan somatische reacties, verstoorde sekslevens, intrusieve gedachten (opdringerige verontrustende gedachten), een verlies van onschuld en hyperalertheid in zowel hun werk als persoonlijke leven.7 Ofwel, symptomen die consistent zijn met (secundair) trauma en zodoende de nodige aandacht vereisen. In Amerikaans onderzoek werd de mate van plaatsvervangend trauma bij leden van de Association for the Treatment of Sexual Abusers (ATSA) en de American Professional Society on the Abuse of Children (APSAC) vergeleken. Hieruit bleek dat mensen die met de daders van zedendelicten werken qua traumasymptomen niet significant verschilden van mensen die met de slachtoffers ervan werken. Voor beide groepen gold dat de mate van plaatsvervangend trauma voor de meerderheid (52\%) binnen het klinische bereik viel $^{9}$ (ofwel voldeed aan de criteria voor diagnostisering van psychopathologie).

Het werk met zedenplegers lijkt dus een belangrijke impact te hebben op het welzijn van de betrokken professionals. Het is echter opvallend dat er zowel in de praktijk als in de literatuur nog relatief weinig aandacht naartoe gaat. Daar wil de Nederlands-Vlaamse tak van ATSA (NL-ATSA) verandering in brengen. NL-ATSA richt zich op de preventie van seksueel geweld en op de behandeling van zedenplegers. Om de impact van het werken met zedenplegers meer onder de aandacht te brengen organiseerde de vereniging recentelijk een symposium. Vier sprekers werden hiervoor uitgenodigd. Zij bespraken onder andere de mentale weerbaarheid en copingstrategieën van kinderpornorechercheurs, de prevalentie en ernst van (seksuele) agressieve incidenten in een tbs-kliniek, hoe collega's elkaar kunnen steunen na een incident met een cliënt en hoe je als professional grensoverschrijdend gedrag vanuit de cliënt kunt halt houden. In dit artikel wordt verslag gedaan van deze dag om het onderwerp meer onder de aandacht te brengen.

\section{Het symposium: de deskundigen aan het woord}

Op 26 maart 2019 kwamen professionals van onder andere politie, justitie en forensische centra in de Utrechtse Van der Hoevenkliniek bijeen voor een dag die in het teken stond van de impact van het werken met zedendelinquenten. NLATSA-voorzitster Marije Keulen-de Vos (de Rooyse Wissel, Venray) wees in haar inleidende woorden op de risico's die praktijkwerkers binnen deze settings lopen. Deze professionals kunnen in hun werk enerzijds geconfronteerd worden met gewelddadig gedrag van een patiënt/cliënt, wat een impact kan hebben op hun welzijn en zelfs tot een posttraumatische stressstoornis kan leiden. Anderzijds lopen zij ook kans op secundaire traumatisering. Secundaire of plaatsvervangende trauma's hebben betrekking op de gedrags- en emotionele gevolgen van blootstelling aan traumatische gebeurtenissen die anderen hebben ervaren of hebben ondergaan. Ook deze traumatische ervaringen kunnen een impact hebben op het

9 I. Way e.a., 'Vicarious trauma: A Comparison of Clinicians Who Treat Survivors of Sexual Abuse and Sexual offenders', Journal of Interpersonal Violence 2004, 19, p. 49-71. 
professionele zelfbeeld, interpersoonlijke relaties en het gedrag van professionals. Hoewel personen die in de forensische geestelijke gezondheidszorg werken geïdentificeerd worden als personen met een verhoogd risico op secundair trauma, ${ }^{10}$ constateerde Keulen-de Vos dat er vrij beperkt onderzoek naar dit onderwerp gedaan is, laat staan naar traumatische ervaringen bij professionals die werken met zedendelinquenten.

\section{De impact van schokkende beelden}

De eerste spreker, Henk Sollie (Twynstra Gudde, Amersfoort), verhaalde over de mentale weerbaarheid van kinderpornorechercheurs. Door middel van observatie- en dieptestudies onderzocht Sollie bij verschillende rechercheteams wat zij zelf als belastende werkomstandigheden ervaren en hoe zij daar in hun specifieke werkcontext mee omgaan. ${ }^{11}$ Uit zijn studie bleek dat veel rechercheurs op een bepaald moment in hun carrière symptomen van secundaire traumatisering kunnen ervaren en vertonen, doordat zij onder meer een grote interne en externe druk ervaren om het overweldigende aantal zaken waarmee ze geconfronteerd worden tot een goed einde te brengen. Doordat ze overspoeld worden met dossiers, zijn ze genoodzaakt om keuzes te maken en prioriteit te geven aan bepaalde zaken boven andere, die bijgevolg langer blijven liggen. Veel rechercheurs willen echter de slachtoffers niet 'verlaten' door hun werkopdrachten te veranderen. Ook blootstelling aan verontrustende foto's en video's en intens contact met zowel daders als slachtoffers hebben een enorme impact op hun welzijn en persoonlijke leven. Velen blijven bijvoorbeeld rumineren over (oude) dossiers, ervaren seksuele problemen in hun eigen intieme relatie en/of worstelen met het hebben van lichamelijk contact met hun eigen kinderen (bijvoorbeeld: ga ik in bad met mijn kind, neem ik mijn neefjes en nichtjes op schoot?).

Een belangrijk element bij het kunnen omgaan met de emotionele impact van dit soort zaken is mentale weerbaarheid. Henk Sollie definieert dit als: 'de uitkomst van een copingproces, waarin in- en externe hulpbronnen de medewerker in staat stellen om binnen de taakuitoefeningen adequaat te blijven functioneren gedurende belastende werksituaties en daar duurzaam van te herstellen met behoud van motivatie voor het werk en betrokkenheid bij de organisatiedoelen'. De mentale weerbaarheid wordt dus gezien als een dynamisch proces, zijnde een wisselwerking tussen persoon en omgeving. Professionals leren zich hierbij op verschillende manieren aan te passen aan belastende situaties. De stress die gepaard gaat met blootstelling aan dergelijke traumatische gebeurtenissen, bijvoorbeeld seksueel misbruik van kinderen, kan worden verzacht door adaptieve, proactieve copingstrategieën toe te passen, zoals:

- emotionele distantie: het hanteren van een analytische werkhouding;

- werkdrukregulering: de lat niet té hoog leggen en prioritering van werklast;

- taakgerichte zelfsturing: de regie voeren over de eigen taakinvulling;

10 H.M. Moulden \& P. Firestone, 'Vicarious traumatization: The Impact on Therapist Who Work With Sexual Offenders', Trauma, Violence \& Abuse 2007, 1, p. 67-83.

11 H. Sollie, Alledaagse Magie: mentale weerbaarheid van kinderporno- en forensisch rechercheurs, Den Haag: Boom criminologie 2017. 
- sociale steun: het aanspreken van een informeel ondersteuningsnetwerk;

- betekenis zoeken: zoeken naar persoonlijke zingeving.

De effectiviteit van deze strategieën is ook afhankelijk van de organisatorische aanpak en de beschikbaarheid van middelen voor ondersteuning en opleiding, met nadruk op de gezamenlijke verantwoordelijkheid vanuit de organisatie in plaats van de individuele. Sollie concludeert dat de mentale veerkracht bij deze rechercheurs niet uit zeldzame en speciale kwaliteiten komt, maar eerder beschouwd moet worden als het resultaat van de 'alledaagse magie' van gewone maar essentiële - hulpbronnen.

\section{Incidenten in een tbs-kliniek}

De tweede spreekster, Anneloes Huitema (De Waag, Utrecht), besprak de studie die zij heeft gedaan naar de prevalentie en ernst van agressieve incidenten in de Van der Hoeven tbs-kliniek. ${ }^{12}$ Samen met Nienke Verstegen (Van der Hoeven kliniek, Utrecht) analyseerde zij retrospectief, over een periode van vier jaar, meer dan 3600 agressieve incidenten bij zowel tbs-patiënten als civielrechtelijke patiënten aan de hand van de Modified Overt Agression Scale (MOAS+). ${ }^{13}$ Er wordt bij dit instrument een onderscheid gemaakt tussen verbale agressie, agressie naar goederen, fysieke agressie naar anderen, agressie naar zichzelf en seksuele agressie.

De prevalentie van incidenten lag aanzienlijk hoger in de groep van de civielrechtelijke patiënten. Deze groep wordt vaak in de kliniek opgenomen wanneer zij een crisissituatie ervaren, wat de hogere cijfers deels kan verklaren. Van alle soorten incidenten (verbaal, fysiek, seksueel) kwam verbale agressie (van beledigingen tot bedreigingen) met 2667 meldingen het meest voor. Slechts een minderheid van de incidenten, 157 van de 3600, werd gekenmerkt door seksuele overtredingen (van seksueel getinte opmerkingen naar vrouwelijke stafleden tot verkrachting). Opvallend hierbij is dat er bij driekwart van deze patiënten sprake was van een psychotische stoornis als primaire diagnose en dat bij slechts drie patiënten een parafilie als primaire diagnose was gesteld. Met betrekking tot alle soorten incidenten waren vrouwelijke patiënten verantwoordelijk voor een relatief groter aantal incidenten dan mannelijke patiënten. Opmerkelijk is dat forensische patiënten die een zedendelict hebben gepleegd, minder agressieve incidenten leken te veroorzaken in vergelijking met niet-zedendelinquenten. Het gemiddelde aantal incidenten lag bij zedendelinquenten ongeveer op drie per persoon, waar het bij de niet-zedendelinquenten over zeven incidenten per persoon ging. Ter illustratie besprak Huitema twee casussen van patiënten om de onderzoeksresultaten praktisch te verduidelijken. De ene casus had een seksueel delict (verkrachting) als indexdelict en veroorzaakte zeer veel incidenten, waaronder geen enkele keer een seksueel incident. De andere casus had een agressiedelict (poging tot zware mishandeling) als indexdelict en veroorzaakte juist zeer veel seksuele

12 A. Huitema, N. Verstegen \& V. de Vogel, 'A Study Into the Severity of Forensic and Civil Inpatient Aggression', Journal of Interpersonal Violence 2018, p. 1-19.

13 S.R. Kay, F. Wolkenfeld \& L.M. Murrill, 'Profiles of Aggression Among Psychiatric Patients. I. Nature and Prevalence', The Journal of Nervous and Mental Disease 1988, 9, p. 539-546. 
incidenten, naast ook een aantal agressie-incidenten. De spreekster benadrukte dat de aantallen de daadwerkelijke prevalentie van agressieve incidenten waarschijnlijk onderschatten. Vele incidenten zouden immers niet gemeld en dus niet geregistreerd worden.

\section{Collegiale ondersteuning en weerbaarheid}

In de laatste twee presentaties bespraken Nicole Strijbos (de Rooyse Wissel, Venray) en Maarten Hoogslag (Nederlands Instituut voor Psychotrauma, expert schokkende gebeurtenissen) hoe professionals veerkrachtig kunnen blijven in het werken met zedendelinquenten. Nicole Strijbos is behalve beeldend therapeute binnen FPC de Rooyse Wissel tevens lid van de Collegiale Opvang en Begeleiding. Deze commissie biedt collegiale ondersteuning wanneer collega's agressieve incidenten of schokkende gebeurtenissen ervaren binnen de instelling. Het primaire doel is de nodige eerste hulp en ondersteuning bieden aan individuele medewerkers bij de verwerking van de gebeurtenissen, alsook het (mede) creëren van een veilige en tot openhartigheid uitnodigende cultuur voor medewerkers. In geval van een incident organiseert de commissie drie gesprekken met de betreffende collega('s). Het eerste gesprek (binnen 24 tot 72 uur na het incident) is gericht op het structureren van informatie, het verkennen van de huidige symptomen (bijvoorbeeld slecht slapen, herbeleven van het incident) en het bieden van hulpmiddelen voor het omgaan met deze symptomen. Het tweede gesprek vindt één of twee weken na het eerste gesprek plaats. Het doel hiervan is om na te denken over de situatie en mogelijke symptomen van trauma te verkennen. Vier tot zes weken na het incident vindt ten slotte het derde gesprek plaats. Tijdens dit gesprek worden de verwerking en de betekenis van het incident behandeld. Indien nodig wordt er verwezen naar een gediplomeerd traumapsycholoog. Het belangrijkste doel van dit ondersteuningssysteem is om betrokkenen weer controle te laten krijgen over zichzelf en de situatie. Nicole Strijbos presenteerde praktijkvoorbeelden en besprak verschillende do's (bijvoorbeeld reageren op gevoelens van collega's, open vragen stellen) en don'ts (bijvoorbeeld gevoelens proberen te temperen en onmiddellijk oplossingen zoeken) die worden vooropgesteld bij het omgaan met collega's die slachtoffer zijn geworden van een incident of een schokkende gebeurtenis hebben meegemaakt.

Het symposium werd afgesloten met een interactieve verdiepingssessie over hoe de professional zich kan weren bij grensoverschrijdend gedrag door de cliënt. In deze sessie ging Maarten Hoogslag eerst in op het ontstaan van een burn-out. Daarna legde hij de focus op vaardigheden die professionals kunnen hanteren ter bescherming van hun eigen psychosociaal of fysiek welzijn. Twee acteurs voerden therapeut-cliëntinteracties uit waarbij telkens de grenzen van de therapeut door de cliënt werden overschreden. De deelnemers werden uitgenodigd om input te leveren voor deze gespeelde situaties. De boodschap van Hoogslag was om de situatie altijd tijdig aan te pakken en duidelijke grenzen te stellen. Vanuit het publiek werd aangegeven dat men niet altijd goed weet wanneer in te grijpen en wanneer mee te buigen. In een situatie waar agressie aan te pas komt, is het belangrijk om helder te hebben of de agressie persoonlijk of onpersoonlijk is. Bij 
onpersoonlijke agressie is het beter om niet té vroeg te temperen, want dan is de kans groter dat de agressie escaleert omdat de 'agressor' zich niet voldoende gehoord voelt. Persoonlijke agressie kan beter snel worden afgekapt door duidelijk te zeggen dat je niet van het betreffende gedrag gediend bent. Een belangrijke tip die Hoogslag meegaf, is om in moeilijke situaties gebruik te maken van een standaard stopzin. Dit kan bijvoorbeeld zijn: 'Oké, vóór we verder gaan...' Ook een handgebaar (bijvoorbeeld een stopteken) kan helpen om je boodschap met de nodige stelligheid over te brengen. Met behulp van een stopzin of -teken kan men zeer duidelijk en op tijd begrenzen. Ook geven deze even de tijd om na te denken, om daarna weer rustig verder te gaan. Dit geldt ook wanneer iemand te dichtbij komt en de persoonlijke ruimte van de therapeut aantast. Ten slotte meende Hoogslag dat men zich als therapeut niet altijd strikt en formeel moet opstellen tegenover de patiënt/cliënt. Bij twijfel over (wat de bedoeling is van) non-verbaal gedrag van de cliënt bijvoorbeeld kan dit best benoemd worden. Een open dialoog en betrokkenheid, maar ook directe communicatie zijn belangrijk. Men mag ook af en toe buiten zijn professionele grenzen treden om dichter bij de leefwereld van de cliënt te komen staan en een evenwaardige gesprekspartner te kunnen zijn.

\section{Conclusie}

Uit het voorgaande blijkt dat het werken met zedenplegers voor de professional moeilijke aspecten met zich brengt en zelfs traumagerelateerde klachten tot gevolg kan hebben. Er dient dan ook adequate aandacht besteed te worden aan het welzijn van deze professionals. Uit de presentaties alsook uit de literatuur blijkt dat ondersteuning uit verschillende hoeken kan komen: persoonlijk (bijvoorbeeld sociaal netwerk, vrijetijdsbesteding, eigen kwaliteiten en humor), professioneel (bijvoorbeeld regelmatige intervisie en supervisie) en organisationeel (bijvoorbeeld duidelijke professionele rol en verwachtingen, behapbare caseload, goede faciliteiten). ${ }^{14}$ Hierbij lijkt vooral het interpersoonlijke aspect van belang; om samen (met naasten, collega's en werkgever) aan zelfzorg te doen en de verantwoordelijkheid niet enkel bij het individu neer te leggen en hem aan zijn lot over te laten. Het is aldus een gedeelde verantwoordelijkheid waar niet alleen de praktijkwerkers maar ook de organisatie zich voor dient in te zetten. Uit de resultaten van een Amerikaanse studie naar secundaire traumatische stress bij 365 zorgprofessionals (maatschappelijk werkers, verpleegkundigen, therapeuten, psychologen en dokters) bleek dat zelfzorg en sociale steun vanuit vrienden en familie secundaire traumatische stress negatief voorspelden, en dat humor, zelfzorg en steun van collega's posttraumatische groei (positieve verandering ten gevolge

14 K. Parsonson \& L. Alquicira, "The Power of Being There for Each Other: The Importance of SelfAwareness, Identifying Stress and Burnout, and Proactive Self-Care Strategies for Sex-Offender Treatment Providers', International Journal of Offender Therapy and Comparative Criminology 2019, p. 1-20. 
van trauma) positief voorspelden. ${ }^{15}$ Een initiatief zoals de Collegiale Opvang en Begeleiding in FPC de Rooyse Wissel sluit dus goed aan bij wat professionals (onder andere) nodig hebben. Sowieso lijkt collegiale ondersteuning uitermate belangrijk, ook omdat in verband met geheimhouding en gevoelige onderwerpen minder met de naasten thuis gedeeld kan worden. Idealiter zouden werknemers tijd en gelegenheid moeten krijgen om structurele intervisiemomenten te kunnen inplannen, maar in de waan van (de eisen van) de praktijk is dit dikwijls het eerste dat sneuvelt. Het feit dat dit symposium uitverkocht was en de dankbare feedback tijdens en na het evenement illustreren dat veel professionals worstelen met het omgaan met agressief of grensoverschrijdend gedrag bij (seksuele) delinquenten. Mogelijkheden om best practices en ervaringen uit te wisselen zijn aldus essentieel, wil men het welzijn van de praktijkwerkers beschermen. Daarnaast ligt er voor onderzoekers nog een schone taak om uit te zoeken welke verdere factoren op welke manier invloed hebben op het voorkomen van en omgaan met de negatieve consequenties van het werken met zedenplegers. Deze specifieke groep professionals is nog erg onderbelicht en verdient, ook gezien het belang van hun werk voor de maatschappij, meer aandacht.

15 S. Manning-Jones, I. de Terte \& C. Stephens, 'Secondary Traumatic Stress, Vicarious Posttraumatic Growth, and Coping Among Health Professionals; A Comparison Study’, New Zealand Journal of Psychology 2016, 1, p. 20-29. 